https://doi.org/10.52449/1857-4114.2020.36-2.08

CZU: 159.954:796.333-053.2

\title{
EXPERIMENTAL STUDY ON THE MANIFESTATION OF CREATIVITY IN BEGINNER RUGBY (10-11 YEARS) THROUGH THE TORRANCE TEST
}

\author{
Bulai Veaceslav ${ }^{1}$, ORCID: 0000-0003-2021-5896 \\ ${ }^{1}$ State University of Physical Education and Sport, Chisinau, Republic of Moldova
}

\begin{abstract}
The phenomenon of globalization, increasing computerization, educational technologies, the volume of specific, scientific, technical and technological information are factors that generate the need for specialists who are able to creatively apply the achievements of scientific research in practical (sports) activities and therefore requires their adaptation to the requirements of modern society. The study of the manifestation of creativity in beginner rugby players (10-11 years old) has a special relevance for increasing the level of sports training of future performance athletes. The analysis of the literature reflects the fact that the differences in creativity are varied depending on the sport. In this context, the manifestation in creative rugby players of a creative behavior and its development through the application of synectic can be the subject of a separate research and effective practical recommendations.
\end{abstract}

Keywords: creativity, rugby players, synectic method, Torrance test.

Creativity was defined by P. Torrance as the process of appearance of sensitivity to problems, lack of knowledge, their disharmony, inconsistency, etc. search for solutions, hypotheses; checks, modifications and cross-checks of hypotheses; and, finally, the formulation and communication of the result of the decision (1974). To determine exactly what creativity is, Torrance examined at least about fifty formulations.

As a result, he relied on the definition of creativity as a natural process, which is generated by a person's strong need to relieve the tension in a situation of uncertainty or incompleteness. Considering creativity as a process makes it possible to identify both the creativity and the conditions that dress and stimulate this process, as well as the evaluation of its products (results).
At the age of 10-11, children go through adolescence, an important moment that will affect the child's entire life. A special problem is that parents do not understand the characteristics of children of this age, and their abuse and dissatisfaction only make the situation worse. It is important to understand that this age is a difficult time for a teenager, as he is aware of the changes in his own life. Therefore, the adolescent needs the support of adults, which requires them to pay more attention and a communication based on trust.

Psychopedagogy specialists consider this age to be the end of childhood with the effect of a series of changes, including self-esteem. School, friends, games, including (dynamic) movement are factors that often change his plans for the future. It is also characterized by a variety of specific elements reflected in Figure 1. 
the adolescent himself

understands that he has grown

up, which leads to a change in

his personal status

\section{Elements specific}

to adolescence

among adults, it distinguishes those who enjoy authority by selecting them as role models the behavior is normalized, and

ready for a dialogue with

parents

\section{Fig. 1. Elements specific to adolescence}

At this point, most children recognize the authority of their parents, being attracted to them, manifesting a strong desire to find themselves in a new world, that of adults. Thus, communication with adults generates and stimulates the need to receive praise, encouragement from close relatives, teachers and coaches (as appropriate).

The respective age is also characterized by an inappropriate behavior of the adolescent being to the detriment of the parents' wishes, which generates questions, quarrels and scandals.

An important factor that contributes to the understanding of adolescents is that adults understand them in terms of personal facts / memories from the same age. In this context, parental patience should prevail.

Among the positive manifestations of this age we can list:

$>$ increasing independence, feeling and responsibility for individual actions;

$>$ expanding interests;

$>$ the emergence of future plans.

Adolescents can manifest their positive qualities of age only in the conditions of an adequate education, which will identify an improvement of their mental development. The main thing is to make the transition to adolescence smooth. To this end, it is important to gradually increase adolescents' obligations and responsibilities.

Negative manifestations of adolescents are characterized by the following features:

$>$ children already fully understand everything, but cannot always react appropriately to what has happened, and their behavioral traits remain prevalent;

$>$ correct education must continue so that the negative manifestations of age are not highlighted;

$>$ frequent mood swings;

$>$ a great desire to give up their childhood and everything connected with it;

$>$ protests against bans.

Behavior changes can be very violent, as prohibitions from parents have the effect of quarrels, causing aggression and irritability. In this case, unfortunately, it is unlikely that the advice will have an effect on you, as we are dealing with the peculiarities of age. Thus, parents need to develop an optimal "Refusal System". Maybe it's worth not only saying "no" but explaining the reason for the refusal.

Common problems for all teenagers:

$>$ high level of anxiety, lack of selfconfidence;

$>$ in boys there is concern that development is too slow;

$>$ girls start to worry about their appearance, being overweight; 
$>$ hormonal activity begins, and children show an interest in sexuality and personal life;

$>$ the period of first love begins;

$>$ manifests a desire for freedom and independence;

$>$ parents and adults are respected, but teenagers still prefer friends.

The basic experiment was performed with two groups of athletes-beginners aged $10-11$ years, 20 each.

The experiment aimed to assess the level of creativity in beginner rugby players aged 10-11; assessing the difference between nonrugby players and beginner athletes regarding the development of creativity at the age of 1011 ;

In the research we started from the hypothesis that probably from the age of (1011) years there could be some differentiations of the development and manifestation of creativity in the urban-rural environment.

Methodology used in the research: Torrance test of creative thinking (T.T.C.T.); Creativity according to Torrance (from lat. Creatio - creation) is a sensitivity to tasks, deficits and gaps in knowledge, a desire to combine various information; creativity reveals the problems associated with the disharmony of the elements, seeks their solutions, presents hypotheses and hypotheses about the possibility of solutions; it verifies and refutes these hypotheses, modifies them, verifies them again, and finally substantiates the result.

These results obtained in our experiment show that: $40 \%$ of novice athletes showed a low degree of creativity, $39 \%$ showed an average degree of creativity and only $21 \%$ are creative enough for this age.

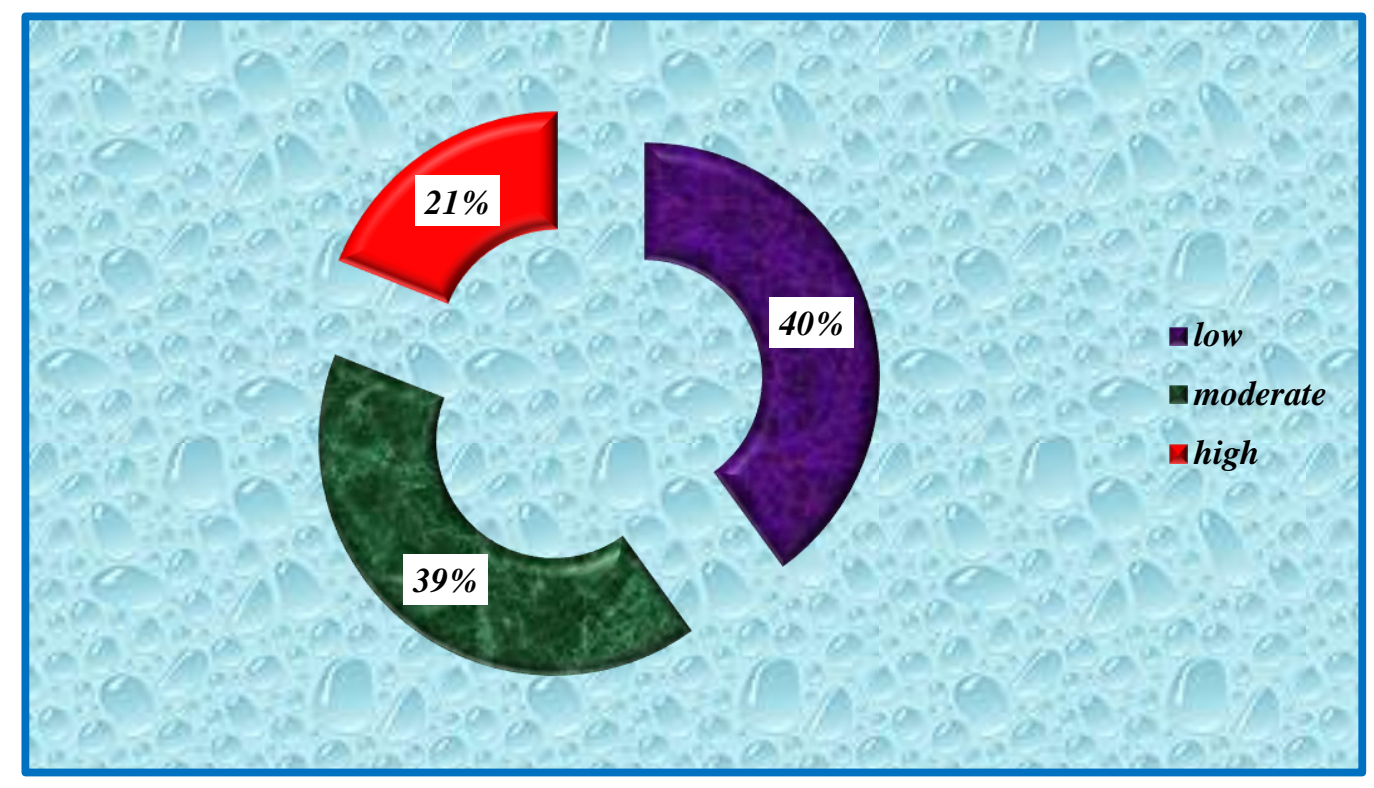

Fig. 2. Percentage of athletes - beginners following Torrance testing

Thus, only one fifth (25\%) of the athletes studied recorded results that demonstrate the high degree of creativity.

The data obtained are contradictory to what we have previously proposed regarding the development and practice of an increased degree of creativity in novice athletes.

The results are also confirmed by the indices recorded by the novice athletes in the next test. 


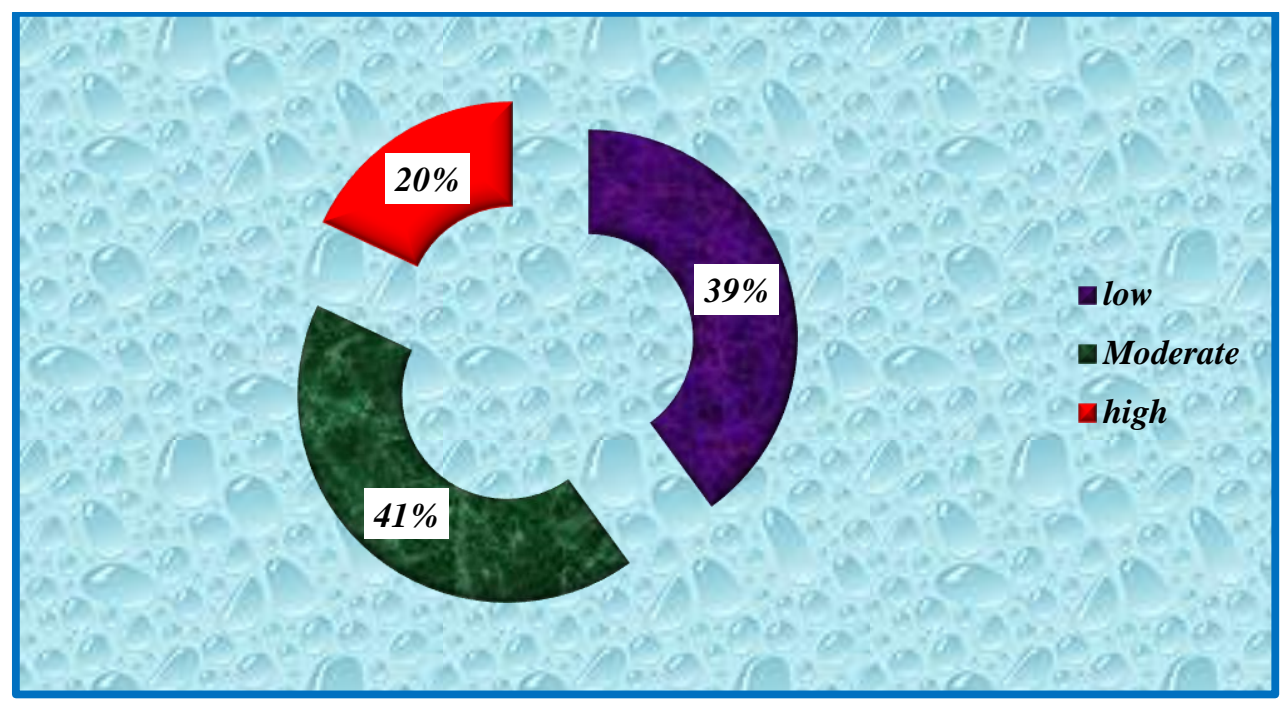

Fig. 3. Percentage recorded on figurative creativity

Piloting the test showed similar indicators compared to those obtained in the previous test with some insignificant differences. $39 \%$ of beginner athletes registered full indices that demonstrate a diminished degree of creativity, $41 \%$ of athletes get full indices that reflect an average level and $20 \%$ recorded indicators that correspond to the increased level of figurative creativity.

The indicators / percentage recorded at this stage showed that almost half of the athletes registered an insufficient degree of creativity - $(40 \%)$. The previously mentioned regarding the diminution of the degree of creativity at this age, the fact demonstrated in the works in particular, conditioned by the transit towards the predominant way of a new activity (Torrance E.P. 1968).

At the next stage of the research we tried to determine the differences between those who do not practice the creative program (control group) and athletes-beginners (rugby) regarding the development of creativity at the age (10-11) years experiment group, at the initial stage.

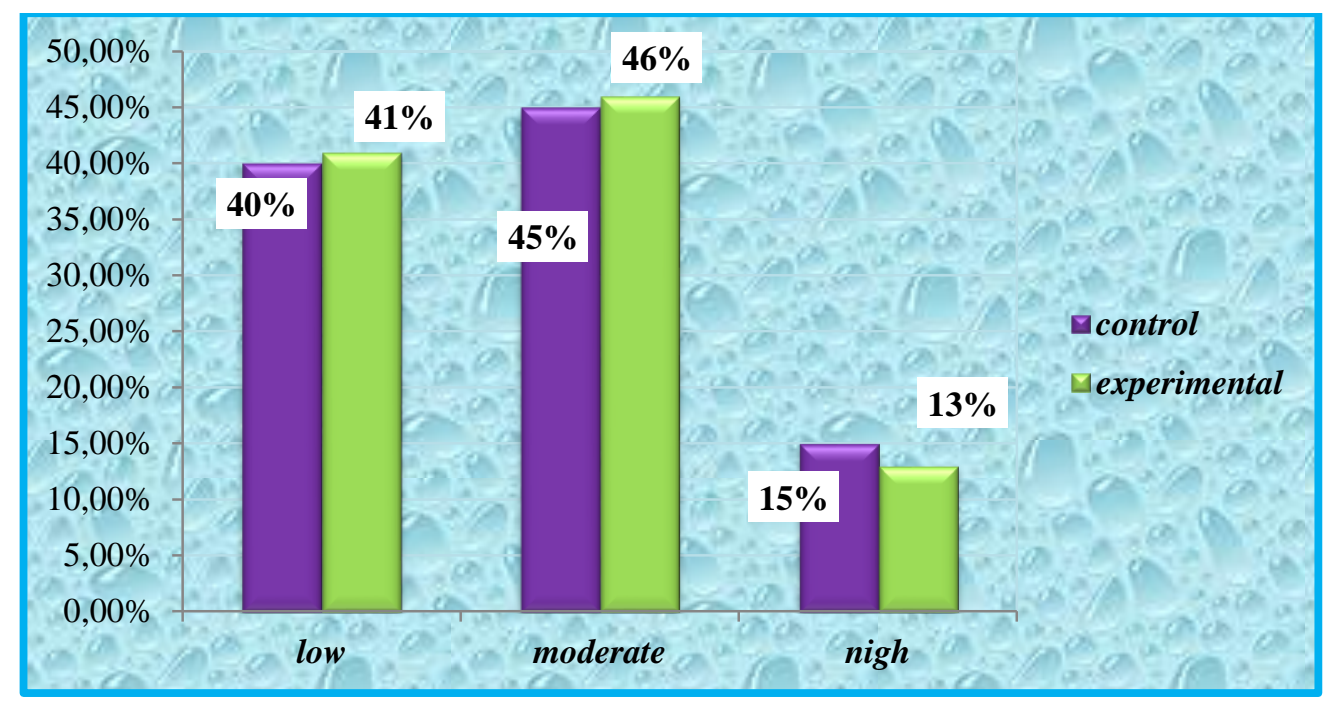

Fig. 4. Athletes' results on the level of creativity in the control and experimental groups, at the initial stage $(n=40)$ 
The data presented in Figure 4 allow us to find that the low level of creativity was obtained by $40 \%$ control group and $41 \%$ experiment group, at the initial stage of the experiment, it shows that the groups were homogeneous. Regarding the moderate degree of creativity, $45 \%$ of the control group and $46 \%$ of the experiment group were registered, and the high level of creativity of the control group registered $15 \%$ compared to the experimental one, which obtained a percentage of $13 \%$. The registered statistical results allow us to mention that there are no statistically insignificant differences regarding the evaluation of creativity (low and high degree) between the control and the experimental group.

After piloting the creative program, the results were significant regarding the manifestation of creativity between the control group and the experiment group only at the high level where in both groups a percentage increase was observed, in the respective control group the creativity increased by $4 \%$, while in the experimental group the increase was of $12 \%$ (Figure 5).

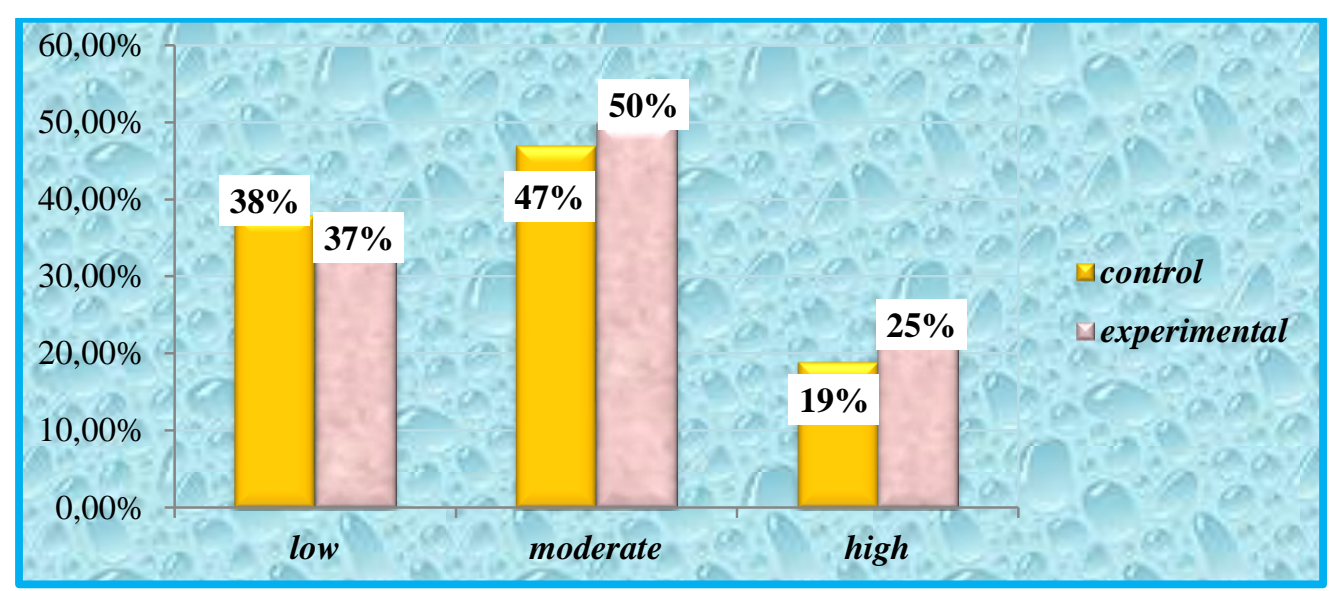

Fig. 5. Athletes' results on the level of creativity of the control and experiment groups at the final stage $(n=40)$

So we can say that creativity in rugbybeginner athletes is better developed (higher level) in the experimental group that followed the creative program focused on the synectic method compared to the control group, which practiced this sport according to the traditional method (Figure 6).

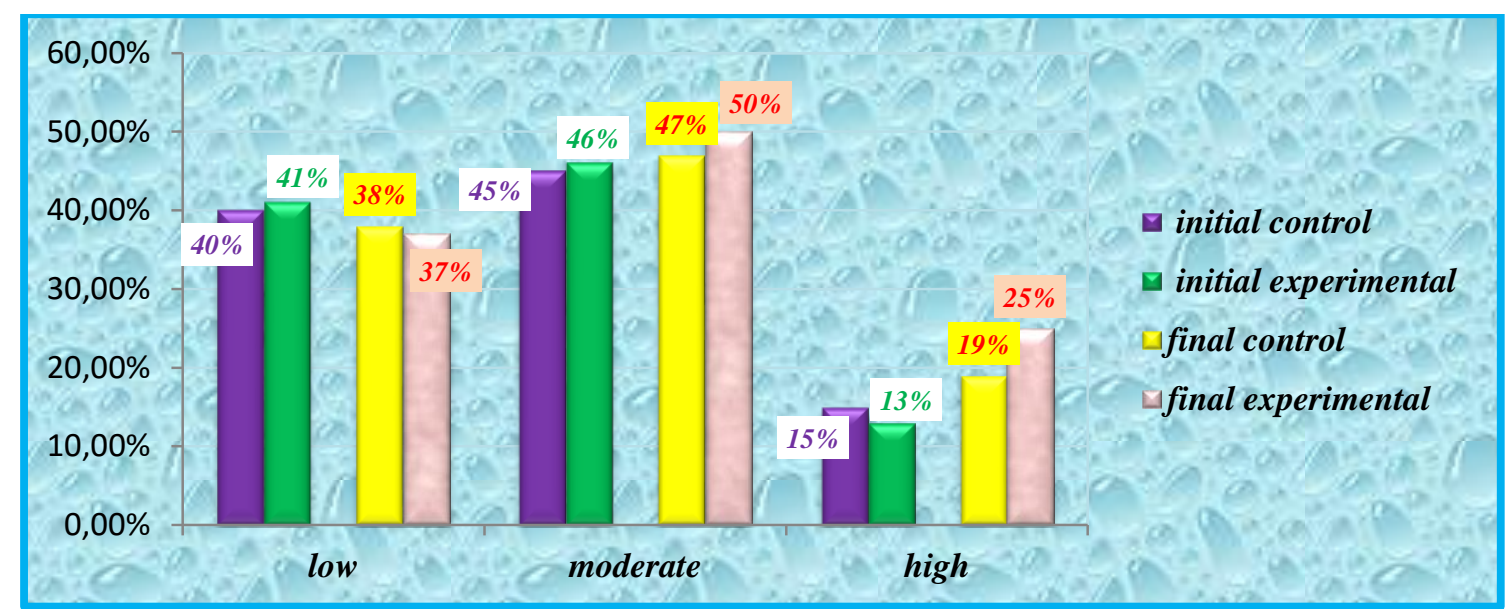

Fig. 6. Athletes' results on the level of creativity in the control and experiment groups at the initial and final stage $(n=40)$ 
In conclusion, we can say that the creative program focused on the synectic method contributes to a greater extent to increasing the creativity of rugby athletes - beginners compared to traditional methods.

Thus, the following data were recorded at the initial and final stage of the experiment:

$\checkmark$ the initial control group recorded a percentage of $40 \%$ of the level of creativity (low), and the initial experiment group a percentage value of $41 \%$; at the final stage of the experiment the control group obtained values of $38 \%$ compared to the experimental one of $37 \%$;

$\checkmark$ the initial control group recorded a percentage of $45 \%$ of the level of creativity (moderate), and the initial experiment group a percentage value of $46 \%$; at the final stage of the experiment the control group obtained values of $47 \%$ compared to the experimental one of $50 \%$;

$\checkmark$ the initial control group recorded a percentage of $15 \%$ of the (high) level of creativity, and the initial experiment group a percentage value of $13 \%$; at the final stage of the experiment the control group obtained values of $19 \%$ compared to the experimental one of $25 \%$.

The final experimental data confirm the research hypothesis, and the new program developed and implemented based on team games by the synectic method, completed by an educational content, practically appropriate (methodological guide) will certainly contribute to the development of creativity in rugby-beginners.

\section{References:}

1. Torrance E.P. (1964). Guiding Creative Talent. Englewood Cliff.

2. Torrance E.P. (1968). Tests of creative thinking. New Jersey.

3. Feier V.V. (1995). Creativitate şi creativitate managerială. Bucureşti: Editura Expert. $254 \mathrm{p}$.

4. Stoica-Constantin A. (2004). Creativitatea pentru studenţi şi profesori. Iaşi: Editura Institutul European. 254 p.

5. Roco M. (2004). Creativitate şi inteligenţă emoţională. Iaşi: Editura Polirom. 246 p. 